\title{
A prospective study on clinical outcome of humerus shaft fracture and nonunion treated with antero medial plating
}

\author{
Deepak Kaki, T. Naveen Babu*, Sunil Malagan, Karthik Gudaru, Jagadesh Gudaru
}

Department of Orthopaedics, BIRRD (T) Hospital, Tirupati, Andhra Pradesh, India

Received: 28 September 2019

Revised: 09 December 2019

Accepted: 11 December 2019

\author{
*Correspondence: \\ Dr. T. Naveen Babu, \\ E-mail: naveen782@gmail.com
}

Copyright: (C) the author(s), publisher and licensee Medip Academy. This is an open-access article distributed under the terms of the Creative Commons Attribution Non-Commercial License, which permits unrestricted non-commercial use, distribution, and reproduction in any medium, provided the original work is properly cited.

\begin{abstract}
Background: Humeral shaft fractures have an incidence of 13 per 100000 per year and account for $3 \%$ of total fractures. The following study is carried out with intention for determining and verifying facts around plate osteosynthesis on anteromedial surface of humerus through anterior approach.

Methods: This is a prospective study of 38 patients presenting with humerus shaft fracture and non-union to the Balaji Institute of Surgery Research and Rehabilitation for the Disabled (BIRRD) from April 2015 to March 2016. Inclusion criteria were age $>18$ years, acute humerus shaft fractures and nonunion of humerus shaft. Exclusion criteria were undisplaced fractures, fractures associated with neurovascular injury, compound and pathological fractures, infected non unions. The functional outcome was graded based on the QuickDASH score. Fisher's exact test was used to find the association between categorical data.

Results: Clinical union was noted in $87 \%$ of the patients and radiological union in $74 \%$ at the end of three months. The average time period required to achieve union was 13.57 weeks. Based on Quick DASH score, $66 \%$ of them had excellent outcome, $24 \%$ had good outcome, $10 \%$ had fair outcome, and none had poor outcome.

Conclusions: It may be concluded that, anteromedial plating through anterior approach for the treatment of humerus shaft fractures and non union leads to a satisfactory functional outcome in most of the patients. Most of the fractures were united by 3 months with good range of motion of shoulder and elbow.
\end{abstract}

Keywords: Humerus shaft fracture, Anteromedial plating, Plate osteosynthesis

\section{INTRODUCTION}

Humeral shaft fractures are relatively common fractures presenting to trauma services, with an incidence of 13 per 100000 per year and account for $3 \%$ of total fractures. ${ }^{1}$ The incidence shows bimodal distribution with peak incidence for males between 20 to 30 years of age and a second peak for older females aged between 60 and 70 years. ${ }^{2,3}$ The rate of non-union reported following open reduction and internal fixation or closed IM nailing is up to $13 \%$. Operative options include plate osteosynthesis and intra medullary nailing. Both methods of fixation are having their own pros and cons. Common benefit being early mobilization, which may lead to earlier functional recovery and reduced pain. ${ }^{4,5}$ With benefits like early mobilisation, rigid fixation, reduced complications and opportunity to address problems like primary radial nerve injuries there is a growing interest in treating humeral shaft fractures by plate osteosynthesis. ${ }^{6,7}$ Further the debate on best approach for plate osteosynthesis shows benefit and limitations of various approaches like posterior, anterolateral, anterior and medial. By placing the plate on the medial surface, excessive soft tissue dissection for visualization and preservation of the radial 
nerve is not required. Anteromedial surface being relatively flatter, plate contouring is less frequently required. The following study is carried out with intention for determining and verifying facts around plate osteosynthesis of anteromedial surface of humerus through anterior approach.

\section{METHODS}

This study was conducted in Balaji Institute of Surgery, Research And Rehabilitation For Disabled, Tirupati, Andhra Pradesh (BIRRD) during the period from April 2015 to March 2016.

Study design: The study design was a one year prospective study.

Sample size: A total of 38 cases were enrolled in the study.

\section{Inclusion criteria}

Patients with age $>18$ years, with acute humerus shaft fractures, those with nonunion of humerus shaft and patients who are medically fit for surgery.

\section{Exclusion criteria}

Patients with undisplaced fractures, those who have fractures associated with neurovascular injury, compound and pathological fractures and those who have infected non unions

\section{Examination and evaluation}

A careful history was elicited from the patients and/or attendants about age, sex, details of injury, history of previous treatment and duration. Patients were evaluated for associated medical problems and associated injuries. These findings were recorded on predesigned and pretested proforma. The local examination of the injured arm was done to look for the attitude, swelling, deformity and loss of function. Any nerve injury was also carefully looked for and noted. Fracture was stabilized temporarily by POP U- slab and arm sling in case of acute cases.

\section{Investigations}

Routine blood examination for hemoglobin \%, total and differential counts, ESR, blood grouping and Rh typing, blood urea, serum creatinine, random blood sugar and coagulation profile. Routine urine examination. HIV- I \& II, HBsAg, ECG, Echocardiography. X-ray- Humerus Anteroposterior And Lateral Views.

\section{Anaesthesia}

Brachial block or general anaesthesia was used in the patients according to their medical condition.

\section{Patient position and draping}

Patients placed in supine position on operating table with extended arm board. Limb is draped from shoulder to elbow joint.

\section{Surgical procedure}

Surgical approach performed was anterior approach. The incision should begin 5 to $7 \mathrm{~cm}$ distal to the coracoid process, which is palpated in deepest point in the concavity of the clavicle distally towards acromioclavicular joint. A 10 to $15 \mathrm{~cm}$ incision was taken in the middle of arm. Fascia over the biceps muscle was split open and muscle was retracted medially. The underlying brachialis muscle was elevated from its medial margin, lifting along with the musculocutaneous nerve. The radial nerve can be located either at the lateral edge of the brachialis muscle or inside the lateral part of the muscle.

\section{Instruments and implants used}

Locking compression plates/ dynamic compression plate of varying length, Drill bit and sleeve for $4.5 \mathrm{~mm}$ system, Power drill, Tap for $4.5 \mathrm{~mm}$ cortical screws and $4.5 \mathrm{~mm}$ depth gauge, Hexagonal screw driver for $4.5 \mathrm{~mm}$ cortical screws and locking screw driver, General instruments like retractors, periosteal elevators, reduction clamps, bone levers etc.

\section{Procedure}

All patients received a prophylactic dose of $1 \mathrm{gm}$ ceftriaxone intravenously preoperatively. The surgery was done in supine position, under brachial block or general anesthesia. Through anterior approach, the fracture site was exposed and reduced with minimal soft tissue dissection. Anatomical reduction of fracture ends is attained. In cases of non union, the medullary cavity of both the ends was opened with rigid reamers till fresh medullary bleed was noticed. In cases of hypertrophic non union, the exuberant callus from medial surface was excised in order to make the plate to sit in congruence with medial surface. The excised callus is placed at the fracture site after plate fixation. In case of atrophic non union, the ends were freshened till the bleeding was noted from the cut ends. Decision to harvest bone graft from iliac crest was then made according to the intra operative findings. The cancellous bone graft was placed at fracture site and once the acceptable reduction was obtained, the plate was placed on the medial surface of shaft and fixed with screws. Wound was closed in layers over drain under negative suction, which was removed after 48 hours.

\section{Postoperative management}

Postoperatively the arm was immobilised in arm sling. After weaning off of anesthesia, signs for radial nerve injury were looked for. Appropriate antibiotics and 
analgesics were used. Immediate posoperative radiographs were taken to check the fracture reduction. Sutures were removed by the $12^{\text {th }}$ day.

\section{Rehabilitation}

Depending upon the pain, shoulder pendulum and elbow range of motion exercises were begun as soon as possible. At first week passive range of motion was started. Active range of motion was started at 3-4 weeks postoperatively, depending on stability of osteosynthesis. At fourth to sixth week immobilization is discontinued. At sixth to eighth week-full range of movements with active exercises were started. Follow-up of patients was done at six weeks, three months and six months following the surgery

\section{Assessment}

For all subjects, radiographs were performed at the end of six weeks, three months and six months of follow-up. Patients were evaluated for clinical union, pain at fracture site, complications, radiological union, range of motion of the shoulder and elbow at the time of discharge and during all three follow-ups.

\section{Final outcome: QUICK DASH evaluation questionnaire}

The QuickDASH ${ }^{8}$ consists of 11 items to measure physical function and symptoms in people with any or multiple musculoskeletal disorders of the upper limb. From the item scores, a summative score is calculated. The final score ranges between 0 (no disability) and 100 (the greatest possible disability). Only one missing item can be tolerated and if two or more items are missing, the score cannot be calculated. Based on the QuickDASH score the functional outcome among patients was graded as excellent outcome 0 to 25 , good outcome 25.1 to 50 , fair outcome 50.1 to 75.0 and poor outcome score $\geq 75$.

\section{Statistical analysis}

Data obtained was coded and entered into Microsoft Excel spreadsheet. The categorical data was expressed as rate, ratio and percentage. The continuous data was expressed as mean \pm S.D. Fisher's exact test was used to find the association between categorical data. A ' $p$ ' value of less than or equal to 0.05 was considered as statistically significant.

\section{RESULTS}

This prospective study was conducted at Balaji Institute of Surgery, Research and Rehabilitation for Disabled (BIRRD), Tirupati, Andhra Pradesh for a period of one year from April 2015 to March 2016. A total of 38 patients sustained with humerus shaft fractures and nonunion were studied. Data obtained was analyzed and the final results and observations were interpreted.
Table 1: Demographic characteristics $(n=38)$.

\begin{tabular}{|lll|}
\hline \multirow{2}{*}{ Age (years) } & Distribution & \\
\cline { 2 - 3 } & Number & \% \\
\hline $\mathbf{1 8 - 3 0}$ & 7 & 18.40 \\
\hline $\mathbf{3 1 - 4 0}$ & 8 & 21.10 \\
\hline $\mathbf{4 1 - 5 0}$ & 10 & 26.30 \\
\hline $\mathbf{5 1 - 6 0}$ & 6 & 15.80 \\
\hline Total & 7 & 18.40 \\
\hline
\end{tabular}

Table 2: Follow up at 6 weeks $(n=38)$.

\begin{tabular}{|llll|}
\hline \multirow{2}{*}{ Variables } & Findings & \multicolumn{2}{l}{ Distribution } \\
\hline \multirow{2}{*}{ Clinical union } & Number & \% \\
\cline { 2 - 4 } & No & 0 & 0 \\
\hline $\begin{array}{l}\text { Pain at } \\
\text { fracture site }\end{array}$ & Yes & 38 & 100 \\
\hline Complications & Yes & 0 & 100 \\
\cline { 2 - 4 } Co & 1 & 0 \\
\hline $\begin{array}{l}\text { Radiological } \\
\text { union }\end{array}$ & Yes & 6 & 37 \\
\cline { 2 - 4 } & No & 32 & 97 \\
\hline
\end{tabular}

Table 3: Follow up at 3 months $(n=38)$.

\begin{tabular}{|llll|}
\hline \multirow{2}{*}{ Variables } & \multirow{2}{*}{ Findings } & Distribution \\
\hline \multirow{2}{*}{ Clinical union } & Yes & 33 & \% \\
\cline { 2 - 4 } & No & 5 & 87 \\
\hline $\begin{array}{l}\text { Pain at } \\
\text { fracture site }\end{array}$ & Yes & 8 & 13 \\
\hline \multirow{2}{*}{ Complications } & No & 30 & 21 \\
\cline { 2 - 4 } & Yes & 38 & 79 \\
\hline $\begin{array}{l}\text { Radiological } \\
\text { union }\end{array}$ & Yes & 28 & 0 \\
\cline { 2 - 4 } & No & 10 & 74 \\
\hline
\end{tabular}

Table 4: Follow up at 6 months $(n=38)$.

\begin{tabular}{|llll|}
\hline \multirow{2}{*}{ Variables } & Findings & Distribution \\
\hline Clinical union & Yes & 38 & \% \\
\cline { 2 - 4 } & No & 0 & 100 \\
\hline $\begin{array}{l}\text { Pain at } \\
\text { fracture site }\end{array}$ & Yes & 0 & 0 \\
\hline Complications & Yes & 38 & 0 \\
\cline { 2 - 4 } & No & 0 & 100 \\
\hline $\begin{array}{l}\text { Radiological } \\
\text { union }\end{array}$ & Yes & 38 & 0 \\
\cline { 2 - 4 } & No & 0 & 100 \\
\hline
\end{tabular}

In the present study $53 \%$ of the patients were males and $47 \%$ were females. Age distribution is evenly distributed and most of the patients presented with age between 41 to 50 years. The mean age was 45.23 years. $61 \%$ of the patients presented with road traffic accident and $39 \%$ with history of fall as nature of trauma. $71 \%$ of the patients presented with fresh fractures and $29 \%$ with non- 
union. Out of total 27 cases of fresh fractures, $67 \%$ of the patients presented with Type-A fracture, $22 \%$ with Type$\mathrm{B}$ fracture and $11 \%$ with Type-C fracture of the humerus shaft according to AO classification. Out of 11 non-union cases, $73 \%$ were of hypertrophic type and $27 \%$ were of atrophic type.

In the present study at first follow up at six weeks, pain at fracture site was noted in all the patients (100\%), radiological union in $6(16 \%)$ patients and one patient (3\%) had wrist drop. Physiotherapy for wrist drop patient was started immediately and patient was given dynamic cock up splint. During second follow up at three months, clinical union was noted in $87 \%$ of the patients and radiological union in $74 \%$. Pain at fracture site was reported by $21 \%$ of the patients and no complications were observed. The patient who had wrist drop, recovered completely during the second follow up. Compared to first follow up, 33 patients attained clinical union, 30 patients were relieved of pain at fracture site and 22 more patients attained radiological union. The average time period required to achieve union was 13.57 weeks.

Based on Quick DASH score, 66\% of them had excellent outcome, $24 \%$ had good outcome, $10 \%$ had fair outcome, and none had poor outcome. Total $90 \%$ of patients had excellent and good outcome. For statistical analysis excellent and good results are taken as acceptable and fair and poor results are taken as non-acceptable.

Table 5: Final outcome based on QUICK DASH score $(\mathbf{n}=38)$.

\begin{tabular}{|llll|}
\hline Outcome & Score & Distribution \\
\hline Excellent & $<25$ & 25 & 65.78 \\
\hline Good & $26-50$ & 9 & 23.68 \\
\hline Fair & $51-75$ & 4 & 10.52 \\
\hline Poor & $>75$ & 0 & 00.00 \\
\hline
\end{tabular}

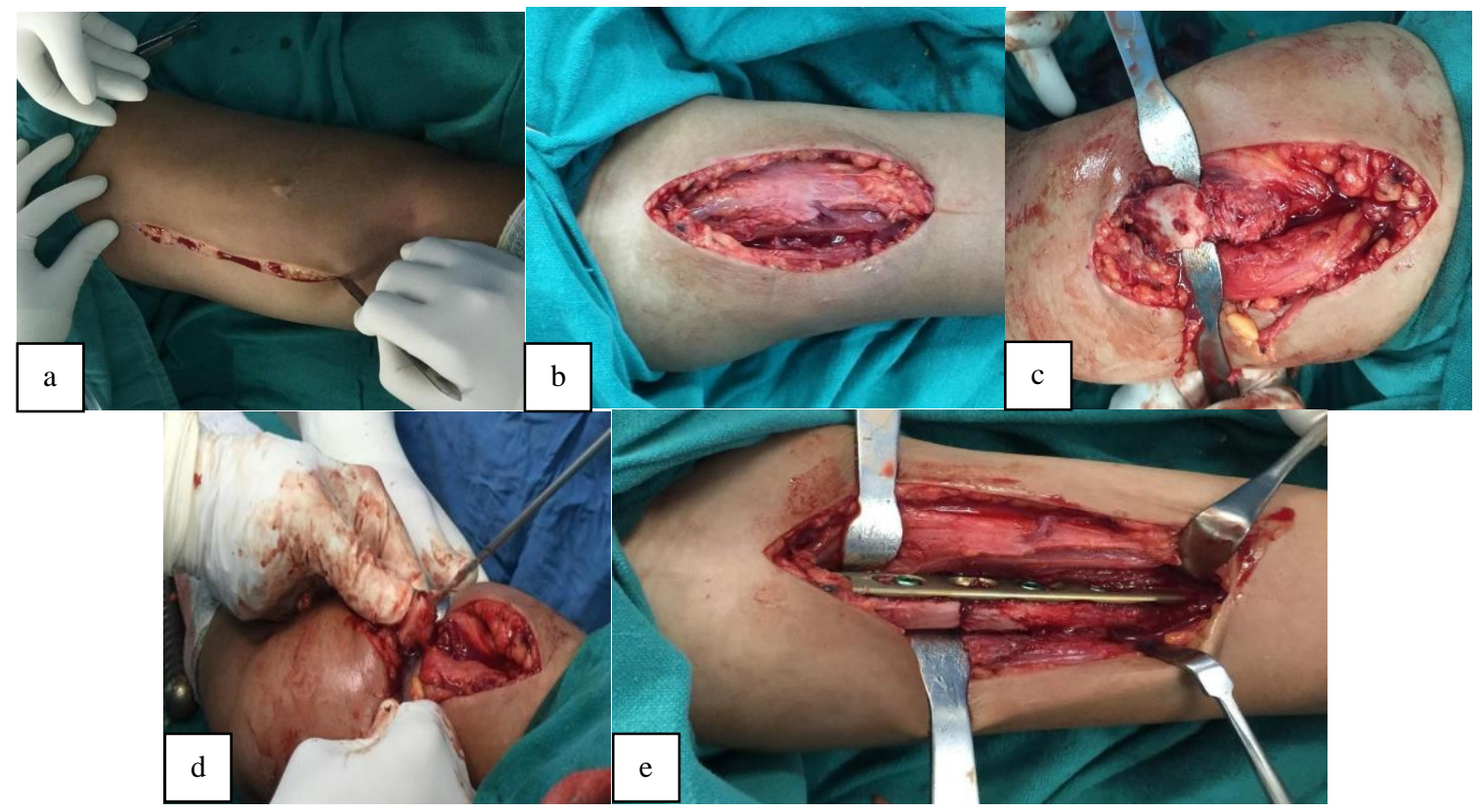

Figure 1: (a) Skin incision, (b) deep dissection, (c) exposure of nonunion site, (d) opening of medullary canal and (e) fracture reduced and fixed with LCP.

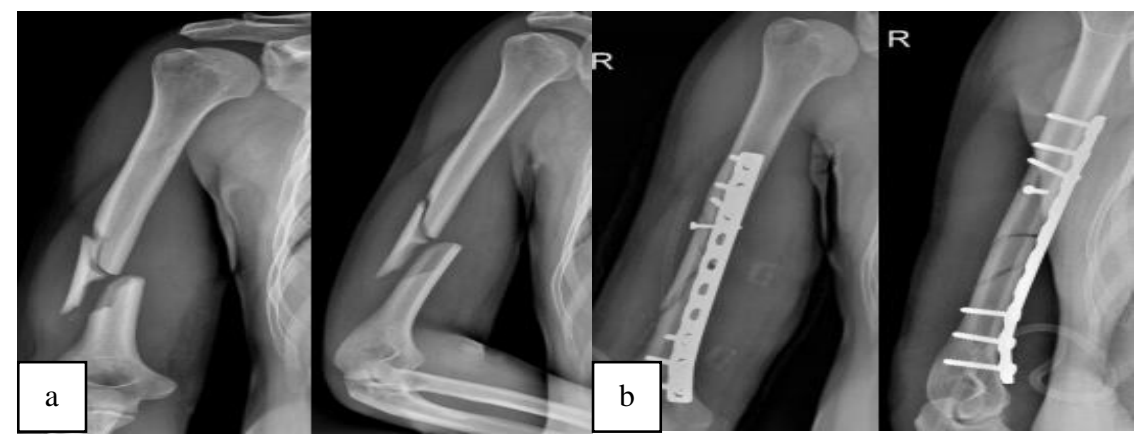

Figure 2: (a) Pre-op radiograph and (b) post-op radiograph. 


\section{DISCUSSION}

In humerus shaft fractures and non-unions, ORIF with anteromedial plate offers good functional outcome with context to the early joint mobilization and rigid fixation of the fracture. The present study was undertaken to assess the efficacy and the functional outcome following internal fixation with anterior approach and anteromedial plate for humerus shaft fractures and nonunions. The posterior and anterolateral plating of humerus are more commonly practiced. Biomechanically, the plate should be placed on the tension side of the injury. The plate should therefore be placed on either the posterior or the anterolateral aspects of the humerus. Unlike the long bones of lower limb, whose primary stresses are weights bearing; the major stresses on the humerus are rotational forces. The plate can therefore be placed on the medial aspect of the humerus.

In this study, 27 patients of fresh fractures were enrolled. Type A, type B and C type of fractures were classified based on AO classification. Accordingly, the type A fractures were noted in most of the cases $(66.67 \%)$ followed by type B (22.22\%) and type C (11.11\%). Wali et al used AO classification for fracture classification. Their study had $64 \%$ of type A, $24 \%$ of type $\mathrm{B}$ and $12 \%$ of type $\mathrm{C}$ fractures. In the present study, out of total 11 non-union cases, $72.73 \%$ of patients were of hypertrophic type and $27.27 \%$ of cases were of atrophic type. Anthony et al classified non unions in their study as hypertophic and atrophic. ${ }^{9}$ Their study too had most of hypertrophic non unions $(81.8 \%)$.

In the anterolateral plating, soft tissue dissection may demand partial or complete erasing of deltoid insertion. The reported incidence of radial nerve palsy is $5.4 \%$ in anterolateral plating. In posterior plating, the incidence of radial nerve palsy is $11.4 \%$. Anteromedial plating avoids radial nerve visualization and dissection, protecting the neurovascular structures. In the present study, we used anterior approach and placed the plate on anteromedial surface. The studies in which plate was positioned on medial surface, by Kirin et al, Senthil et al, Dayez et al concluded that, there was no requirement for blood transfusion for any of the patients, radial nerve palsy was not observed in any of the case immediately after surgery. ${ }^{10-12}$ Evidence of union was seen between six to twelve weeks. Our experience was same regarding the need of blood transfusion, time period of healing, simplicity of procedure, safety and time duration of surgery. Outcome of our study which was not consistent with others is, post-operative wrist drop. No study where anteromedial plating was performed, showed incidence of secondary radial nerve palsy. In present study, one patient (2.63\%) had wrist drop immediately after surgery and recovered completely with physical therapy by 3 months post-surgery. Other studies by Kirin et al and
Senthil et al in which plate was placed on medial surface did not show wrist drop. ${ }^{10,11}$

Majority of the patients had clinical (87\%) and radiological union $(74 \%)$ during second follow up at three months. The range of motion at first, second and third follow ups showed gradual increase in mean flexion, abduction, external rotation and internal rotation. These findings suggest that internal fixation with anteromedial plate for humerus shaft fractures and nonunion result in overall good results that is nearly $90 \%$ of the patients had excellent and good results. These findings are consistent with study done by Kirin et al and Senthil et al. ${ }^{10,11}$

\section{CONCLUSION}

It may be concluded that, anteromedial plating through anterior approach for the treatment of humerus shaft fractures and non-union lead to a satisfactory functional outcome in most of the patients. With this approach, soft tissue dissection was minimized and the flat medial surface of the shaft of humerus offered an ideal surface for plate positioning by decreasing the need of plate contouring and making the procedure easier. The average time period required to achieve union was 13.57 weeks. But most of the fractures were united by 3 months with good range of motion of shoulder and elbow. The incidence of secondary radial nerve palsy was $2.63 \%$. Though secondary radial nerve palsy is quite rare as per reported literature, one should be watchful while applying traction for reduction, while placing bone clamps and retractors, as we encountered a case of secondary radial nerve palsy which recovered completely with physiotherapy. Anteromedial plating is an ideal construct to use for fractures of the shaft of humerus in AO type-A, type-B and type-C. Satisfactory results were noted in both hypertrophic and atrophic nonunions.

Funding: No funding sources

Conflict of interest: None declared

Ethical approval: The study was approved by the institutional ethics committee

\section{REFERENCES}

1. Tytherleigh-Strong G, Walls N, McQueen MM. The epidemiology of humeral shaft fractures $\mathrm{J}$ Bone Joint Surg [Br]. 1998;80-B:249-53.

2. Walker M, Palumbo B, Badman B. Humeral shaft fractures: a review. J Shoulder Elbow Surg. 2011;20:833-44.

3. Clement ND. Management of Humeral Shaft Fractures; Non-Operative versus Operative. Arch Trauma Res. 2015;4(2):e28013.

4. Mahabier KC, Esther MM, Lieshout V, Bolhuis HW. HUMeral Shaft Fractures: MEasuring Recovery after Operative versus Non-operative Treatment (HUMMER): a multicenter comparative 
observational study. BMC Musculoskelet Disord. 2014;15:39.

5. Denard AJ, Richards JE, Obremskey WT. Outcome of nonoperative vs operative treatment of humeral shaft fractures: a retrospective study of 213 patients. Orthopedics. 2010;33(8).

6. Wali MGR, Baba AN, Latoo IA. Internal fixation of shaft humerus fractures by dynamic compression plate or interlocking intramedullary nail: a prospective, randomised study. Strat Traum Limb Recon. 2014;9:133-40.

7. Li Y, Wang C, Wang M, Huang L, Huang Q. Postoperative malrotation of humeral shaft fracture after plating compared with intramedullary nailing. J Shoulder Elbow Surg. 2011;20:947-54.

8. Hudak PL, Amadio PC, Bombardier C. Development of an upper extremity outcome measure: the DASH (disabilities of the arm, shoulder and hand) [corrected]. The Upper Extremity Collaborative Group (UECG). Am J Ind Med. 1996;29(6):602-8.

9. Ayotunde OA, Sunday OK, Oluwatoyin A. Results of surgical treatment of nonunion of humeral shaft fracture with dynamic Compression plate and cancellous bone grafting. Acta Ortop Bras. 2012;20(4):223-5.

10. Kirin I, Jurišić D, Grebić D. The advantages of humeral anteromedial plate osteosynthesis in the middle third shaft fractures. Sergej. Wien Klin Wochenschr. 2011;123:1-5.

11. Senthil L, Jambu N, Chittranjan BS. Anteromedial Plating of Humerus - an Easier and Effective Approach. Open J Orthop. 2015;5:305-10.

12. Dayez J. Internal screwed plate for recent fractures of the humeral diaphysis in Adults. Rev Chir Orthop Reparatrice Appar Mot. 1999;85:238-44.

Cite this article as: Kaki D, Babu TN, Malagan S, Gudaru K, Gudaru J. A prospective study on clinical outcome of humerus shaft fracture and nonunion treated with antero medial plating. Int J Res Orthop 2020;6:158-63. 